\title{
summary
}

\section{Patients expect dentists to give them advice to quit tobacco use}

Campbell HS, Sletten M, Petty T. Patient perceptions of tobacco cessation services in dental offices. J Am Dental Assoc 1999; 130:219-226

Objective To determine what patients and practitioners think about dentists providing tobacco cessation services (TCS).

Design Questionnaire survey during a randomised controlled trial to improve TCS.

Intervention A self-administered questionnaire to 53 dental practices in Alberta, Canada with a telephone survey of a random sample of patients attending these practices.

Outcome measures Frequencies were used to determine distribution of responses and attitudes were measured on a 3-point scale (comfortable/neutral/not comfortable).

Results Ninety-eight per cent of the dental practices responded and $85.1 \%$ of the patients were interviewed. Overall $58.5 \%$ of patients thought that their dentist should offer TCS whereas $61.5 \%$ of dentists thought that patients did not expect such services. A higher percentage $(69.6 \%)$ of younger patients (15-24 years) thought TCS should not be offered. There were minor differences between users and non-users of tobacco.
Table 1 Response of patients and dentists to TCS questionnaire

\begin{tabular}{lccc}
\hline Population & $\begin{array}{c}\text { Should } \\
\text { offer TCS }\end{array}$ & $\begin{array}{c}\text { Should not } \\
\text { offer TCS }\end{array}$ & Don't know \\
\hline Tobacco users & 59.0 & 27.2 & 13.6 \\
Non-users & 59.2 & 24.1 & 16.2 \\
15-24-year olds & 69.6 & 19.3 & 10.9 \\
Dentists & 38.5 & 61.5 & - \\
\hline
\end{tabular}

Conclusion Most patients believed that dental practices should offer tobacco cessation services but most practitioners did not.

Evidence-Based Dentistry (2002) 3, 16. DOI: 10.1038/sj/ebd/ 6400091

Address for reprints: Dr. HS Campbell, Centre for Behavioural Research and Program Evaluation, National Institute of Canada, University of Waterloo, 200 University Avenue, West Waterloo, Ontario N21 3G1, Canada.

\section{Commentary}

This Canadian study is unique in reporting on the views of practitioners and a sample of their patients regarding the appropriateness of TCS in dental practices. The results indicated that the majority of patients were in favour of these services. There seemed to be greater support from younger patients but inexplicably the authors compared those between 15-24 years of age $(n=467)$ with those over 25 years $(n=2631)$, despite the fact that the mean age of their sample was 40 years (range, 15-96 years).

There was support from both users and nonusers of tobacco. Overall $70 \%$ of the sample reported that they were interested in quitting. Not surprisingly, a higher proportion of these (about $60 \%$ ) said they would be comfortable receiving TCS than those not interested in quitting (40\%). Of those who did not support TCS in dental practice, tobacco users were marginally more likely to respond negatively.

Although most practitioners believed dentists should offer TCS, most thought patients did not expect it. Almost all practitioners were concerned about patient resistance and more than half were worried about patients leaving the practice. In addition $90 \%$ reported a lack of confidence in their ability to provide effective TCS. Some of these findings are reflected in surveys carried out in other countries. $^{1-4}$

The discrepancy between what practitioners perceived patients' expectations to be and what patients reported is interesting. Although a large number of patients reported an interest in stopping tobacco-use, it would be up to the practitioner to identify them and to determine what sort of assistance they required. After all, $40 \%$ of those not interested in quitting reported that they would not be comfortable receiving TCS from the practice, and may indeed be resistant if the subject was raised. In addition, the survey was set in rural communities where access to TCS may be limited, leading patients to expect these services from their healthcare providers. Most practitioners in this survey believed that dentists should provide TCS. In this context, the key therefore would be training for dental care providers, to help them identify those of their patients who would like to stop using tobacco and to provide the appropriate assistance.

1. Clover K, Hazell T, Stanbridge V, Sanson FR. Dentists' attitudes and practice regarding smoking. Aust Dent J 1999; 44:46-50.

2. Chestnutt IG, Binnie VI. Smoking cessation counselling - a role for the dental profession? Br Dent J 1995; 179:411-415.

3. John JH, Yudkin P, Murphy M, Ziebland S, Fowler $\mathrm{GH}$. Smoking cessation interventions for dental patients - attitudes and reported practices of dentists in the Oxford region. Br Dent J 1997; 183:359-364.

4. Skegg JA, McGee RO, Stewart AW. Smoking prevention: attitudes and activities of New Zealand dentists. NZ Dent J 1995; 91:4-7.

Jeyanthi John Centre for Evidence-based Dentistry, Institute of Health Sciences, Oxford, 